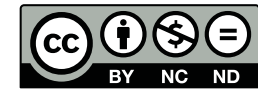

Estudos Teológicos foi licenciado com uma Licença Creative Commons Atribuição - NãoComercial - SemDerivados 3.0 Não Adaptada

http://dx.doi.org/10.22351/et.v57i1.2998

\title{
As mulheres da Reforma na Igreja do Norte da Alemanha: UM OLHAR SOB A PERSPECTIVA DE GÊNERO ${ }^{1}$
}

\author{
The women of the Reformation in the Northern Church of Germany: \\ a look from the gender perspective
}

\begin{abstract}
Karen Bergesch ${ }^{2}$
Resumo: O artigo aborda o tema das mulheres da Reforma desde o século XVI até hoje, propondo uma análise de gênero. Para tanto, é apresentado inicialmente o projeto da exposição itinerante organizada pelo Departamento de Mulheres da Igreja do Norte da Alemanha. A exposição define como mulheres da Reforma aquelas que, ao darem o seu testemunho de fé, contribuíram ativamente para a promoção das ideias de uma igreja sempre em Reforma. A compreensão da Reforma como um processo contínuo extende o movimento histórico desde o século XVI até hoje. A segunda parte do artigo apresenta cinco biografias de mulheres incluídas na exposição em forma de resumo. As biografias narram histórias de mulheres que deram testemunho de fé de forma inovadora, marcando a história da sua região. A terceira parte do artigo realiza uma análise de gênero a partir das mudanças propostas pelo movimento da Reforma aos papéis do masculino e do feminino na sociedade no século XVI. Também são incluídas na análise as situações trazidas pelas biografias, que descrevem enfrentamentos pela liderança de comunidades e no trabalho social, bem como conquistas.
\end{abstract}

Palavras-chaves: Mulheres. Reforma. Gênero. Transformação.

Abstract: The article addresses the theme of women of the Reformation from the sixteenth century until today, proposing a gender analysis. The first part presents the women of the Reformation itinerant exhibition projekt organized by the Women's Desk of the Northern Church of Germany. The exhibition includes those women who, by giving their testimony of faith, have contributed actively to the promotion of the new faith. The Reformation's understanding for the exibition is an ongoing process from the 16 th century until today. The second part presents five women biographies from the exhibition in the form of a summary. The biographies tell stories of women who have witnessed faith in an innovative way, marking the history of their region. The third part of the

1 O artigo foi recebido em 02 de abril de 2017 e aprovado em 05 de maio de 2017 com base nas avaliações dos pareceristas ad hoc.

2 Doutora em Teologia pela Faculdades EST, São Leopoldo/RS, Brasil. Coordenadora do Departamento da América Latina e América do Norte no Centro de Missão e Ecumenismo na Igreja do Norte da Alemanha, Hamburgo, Alemanha. Contato: karenbergesch@t-online.de 
article performs a gender analysis based on the changes proposed by the Reformation movement to the masculine and feminine roles in society in the 16th century. This part includes also the biographies analysis, which describe confrontations in the community leadership and social work, as well as achievements.

Keywords: Women. Reformation. Gender. Transformation.

\section{Introdução}

O presente artigo aborda o tema das mulheres da Reforma, propondo uma análise sob a perspectiva de gênero. Essa proposta enfrenta alguns desafios. Primeiramente, é necessário caracterizar as mulheres da Reforma. Geralmente são incluídas nessa categoria mulheres que deixaram seus nomes registrados através de debates teológicos no século XVI. Mas será que as mulheres da Reforma podem ser restringidas somente a esse grupo?

Segundo, ao refletir sobre essa pergunta, mais um desafio se coloca. Qual seria o período da Reforma exatamente? É correto reduzir o movimento da Reforma ao século XVI? Certamente esse século foi determinante para a Reforma, mas o movimento em si propõe uma continuidade na revisão da fé a partir da Bíblia. Sob tal enfoque, a Reforma aqui é compreendida como um movimento que inicia no século XVI e se extende até hoje.

Ambos os desafios encontram uma resposta na exposição itinerante sobre as mulheres da Reforma, organizada pelo Departamento de Mulheres da Igreja do Norte da Alemanha em comemoração ao jubileu de 500 anos da Reforma. As organizadoras da exposição criaram critérios específicos para encontrar as mulheres da Reforma e o resultado é positivamente surpreendente.

Além disso, a exposição é planejada para ir ao encontro de seu público e não esperar que o público a visite em um único lugar. A exposição está em movimento, assim como a igreja da Reforma. A exposição assume iniciativas, assim como as mulheres da Reforma. Essa é a primeira parte do artigo.

A segunda parte do artigo apresenta o resumo de cinco dentre as 20 biografias da exposição. As biografias resgatam histórias de mulheres que tiveram papel marcante em suas comunidades ao darem testemunho de sua fé. As iniciativas tomadas por essas mulheres geraram resultados de inclusão e de cuidado (diaconia) que chegam aos dias de hoje.

Por fim, o texto propõe uma análise histórica dos papéis e normas referentes ao masculino e ao feminino a partir da categoria de gênero. Que mudanças são propostas? Que mudanças se consolidam? Quais são os papéis e as normas que deixam de seguir o convite para um movimento contínuo de reflexão a partir da igualdade vinda com o sacerdócio universal de todos os crentes? Como foram resolvidos os confrontos de gênero frente ao interesse comum pela liderança? 


\section{A exposição itinerante - um convite ao movimento}

Por ocasião das comemorações do Jubileu dos 500 anos da Reforma Luterana em 2017, estão sendo organizados vários encontros, eventos e publicações nas igrejas luteranas ao redor do mundo já há algum tempo. Diversos grupos e organizações de mulheres, nas igrejas luteranas, buscam visibilizar a participação de mulheres do movimento da Reforma junto a tais festividades através de palestras, publicações de materiais e seminários.

Dentre as numerosas atividades comemorativas para a ocasião do jubileu, a Igreja do Norte da Alemanha (Nordkirche) ${ }^{3}$, através do Departamento de Mulheres (Frauenwerk), propõe uma exposição itinerante, resgatando a participação de mulheres desde o movimento da Reforma até nossos dias. A compreensão para tanto é de que a Reforma não se restringe somente ao período do século XVI, mas é contínua.

Uma igreja em constante movimento de Reforma dialoga com as questões de seu tempo, sendo desafiada e desafiando a sociedade e seus membros continuamente. Ao resgatar a história de mulheres que testemunharam sua fé através de ações concretas na sociedade de seu tempo, registra-se a situação de mulheres em posição de liderança ou na busca por espaços de igualdade e reconhecimento para a liderança. ${ }^{4}$

O título da exposição é ,....von gar nicht abschätzbarer Bedeutung " Frauen schreiben Reformationsgeschichte" (“...de importância não estimável, mulheres escrevem história da Reforma"). A coordenadora geral é a bispa emérita Maria Jepsen ${ }^{5}$ e a organizadora responsável pelo Departamento de Mulheres da Igreja do Norte da Alemanha, Kerstin Klein.

A exposição itinerante percorre 14 cidades entre fevereiro de 2016 e novembro de 2017. Nela, o público encontra 20 biografias que se destacaram tanto no movimento da Reforma como na história da igreja luterana no norte da Alemanha até hoje. A pesquisa revelou um volume inesperado de material, cerca de 60 biografias. ${ }^{6}$

$\mathrm{Na}$ verdade, esse é um longo período que narra a história do próprio país. A perspectiva de incluir histórias de vidas desde o século XVI até hoje amplia a possibilidade de fonte de pesquisa. Desde a Reforma, há mulheres que interagem com modificações políticas, geográfias e econômicas, tendo suas decisões e ações ancoradas na fé e na vivência junto à igreja. Dessa forma, a exposição revela novas histórias e,

3 A Igreja do Norte da Alemanha (Nordkirche) foi fundada como Igreja Territorial (Landeskirche) em 27 de maio de 2012, sendo essa a fusão das Igrejas Regionais de Mecklenburg, Nordelbien e Pommern. Tornou-se, dessa forma, a quinta maior Igreja Territorial, com aproximadamente 2,1 milhões de membros, dentre as 20 Igrejas Regionais filiadas à Igreja Evangélica da Alemanha (EKD). Cf. <www.nordkirche.de>.

4 KOERTGE, Ulrike. 500 Jahre Reformation - und Frauen sind machtvoll dabei! Vorwort von Ulrike Koertge. In: KLEIN, Kerstin; MANSKE, Maike. ,....von gar nicht abschätzbarer Bedeutung “. Frauen schreiben Reformationsgeschichte. Kiel: Lutherische Verlagsgesellschaft, 2016. p. 8.

5 Maria Jepsen, bispa emérita, nasceu em 1945 em Bad Segeberg. Primeira bispa eleita em toda a igreja luterana ao redor do mundo para a região de Hamburgo em 1992. Em 2008, assumiu o Bispado Hamburg-Lübeck, Nordelbische Kirche. Em 2010, aposentou-se. Estudou Teologia em Tübingen, Kiel e Marburgo. Cf. <www.nordkirche.de/de.wikipedia.org/wiki/Maria_Jensen>. Acesso em: 27 mar. 2017.

6 KOERTGE, 2016, p. 8. 
paralelamente, enfatiza a abordagem sobre a Reforma a partir da compreensão de uma igreja em contínua transformação. ${ }^{7}$

Diante do longo período histórico e do volume de material encontrado sob esse novo olhar, foi necessário criar critérios para a seleção das biografias. Os critérios definidos foram: 1. apresentar pelo menos uma biografia oriunda de cada distrito eclesial; 2. apresentar pelo menos uma representante de cada século; 3. encontrar o maior número possível de representantes de diferentes campos de atividades; 4. registrar ações que ainda são relevantes para os dias de hoje; 5. selecionar biografias que reflitam um diálogo com a sociedade na perspectiva da fé.

A partir desses critérios, nenhuma representante da Reforma deveria ser ignorada. ${ }^{8}$ Estabeleceram-se também os objetivos específicos:

- Mudar a perspectiva: dirigir a atenção do olhar para as mulheres e compreender a Reforma como um processo contínuo até hoje.

- Fomentar o conhecimento sobre as mulheres nesse período histórico e perceber a importância de suas vidas para o contexto de hoje.

- Estimular a identificação das pessoas com essas biografias para que elas busquem ampliar o conhecimento sobre a cultura local.

- Impulsionar as mulheres de hoje a continuarem o movimento da Reforma a partir de questões atuais.

- Incentivar a integração da Igreja do Norte da Alemanha.

- Resgatar a biografia de mulheres que foram esquecidas nesse período da história. ${ }^{9}$

As biografias encontradas exemplificam a história das mulheres de forma mais ampla na busca por igualdade, respeito, direitos e responsabilidades, incluindo conquistas e períodos de estagnação. As biografias pertencentes à exposição itinerante incluem novos nomes à pesquisa já existente sobre o tema, unindo-se à lista daqueles nomes mais conhecidos como, por exemplo, os de Katharina von Bora e de Argula von Grumbach. ${ }^{10}$

Seguem-se agora o resumo de cinco biografias incluídas na exposição.

\section{Biografias}

Wibe Junge (ca. 1485-?) - coragem em defender as ideias reformadoras

As poucas informações sobre Wibe Junge estão relacionadas ao movimento da Reforma em Dithmarschen. Wibe Junge defendeu Heinrich von Zütphen, que divulgava o pensamento reformador na região. Von Zütphen alcançou grande êxito e,

\footnotetext{
7 KLEIN, 2016, p. 10.

8 KLEIN, 2016, p. 10-13.

9 KLEIN, 2016, p. 10-13.

10 DOMRÖSE, Sonja. Frauen der Reformationszeit, gelehrt, mutig und glaubensfest. Göttingen: Vandenhoeck \& Ruprecht, 2014.
} 
paralelamente, críticas severas. No dia 10 de dezembro de 1524 , foi levado com muita violência da casa onde estava para um local de execução.

Wibe Junge enfrentou a multidão enfurecida e proferiu um discurso em defesa de Heinrich von Zütphen, pedindo que o acusado tivesse direito de defesa diante dos seus acusadores. Para tanto, ele deveria receber alguns dias de prazo a fim de preparar-se para o julgamento. Wibe Junge se dispôs a pagar um valor para garantir o direito de defesa do acusado. Infelizmente, de nada adiantou seu bravo dicurso. Ela foi jogada ao chão e Heinrich von Zütphen executado.

Wibe Junge teve seus primeiros contatos com o pensamento reformista no ano de 1514, depois da morte do marido. Ela é descrita como uma pessoa estudada, rica e distinta, que promoveu o pensamento da Reforma no lugar onde morava, tendo trocado correspondência com Lutero.

Apesar da execução de Heinrich von Zütphen, as ideias reformistas continuaram se espalhando, e oito anos depois a Reforma instalou-se definitivamente na região. Igrejas e escolas católicas passaram a ser luteranas. Wibe Junge não assumiu diretamente nenhum cargo de liderança na nova organização da igreja e das escolas, mas seu nome está relacionado tanto com a divulgação desse movimento religioso quanto com o nome de amigos e familiares que assumiram cargos de liderança. ${ }^{11}$

\section{Duquesa Maria Elisabeth de Schleswig-Holstein-Gottorf (1610-1684) - imprimiu uma versão da Bíblia e um cancioneiro}

Maria Elisabeth nasceu em 22 de novembro de 1610 em Dresden. Sendo de família nobre e religiosa, recebeu uma educação com ênfase em música, línguas e arte, ancorada na fé e nos valores luteranos. A mãe foi responsável por sua educação religiosa. Casou-se aos 19 anos de idade com o duque Friedrich III de Schleswig-Holstein-Gottorf e juntos constituíram uma família.

O casal promoveu a vida cultural, convidando artistas, escritores e músicos de renome para eventos em seu castelo e na região. Ao ficar viúva, Maria Elisabeth continuou promovendo a vida cultural e religiosa. Grande destaque recebem suas iniciativas de imprimir uma versão da Bíblia (1664) para ser utilizada nos cultos de Husum. Outra iniciativa de grande louvor é a compilação de um livro de canto (1676), com uma tiragem de 110 exemplares. Devido à sua boa formação humanista e a seus contatos nessa área, procurou garantir a qualidade das publicações convidando pessoas competentes para trabalhar nos projetos.

Maria Elisabeth era conhecida não só pelo seu amplo conhecimento cultural, mas também por ser uma pessoa religiosa e piedosa. Seu testemunho de fé na sociedade, na família, junto aos empregados e na promoção da vida comunitária através de doações e presentes tornou-a uma pessoa amada e respeitada. Dessa forma, Maria

${ }_{11}$ MURY, Nanna; MANSKE, Maike. Wibe Jung, ca. 1485 - unbekannt. „Da trat hinzu eine fromme christliche Frau, wohnhaft zu Meldorf“. In: KLEIN; MANSKE, 2016, p. 19-23. 
Elisabeth passou a ser a imagem ideal de uma princesa. Seu incentivo à fé luterana foi determinante para o desenvolvimento da igreja luterana no norte da Alemanha. ${ }^{12}$

\section{Amalie Sieveking (1794-1859) - iniciativas diacônicas}

A Igreja do Norte da Alemanha assume como data oficial de início dos trabalhos diacônicos a fundação da Rauhes Haus por Johann Hinrich Wichern no ano de 1848 em Hamburgo. Esse é um dos centros de diaconia mais antigos do país. ${ }^{13}$ No entanto, em anos anteriores, já haviam sido realizados trabalhos diacônicos por iniciativa de algumas mulheres. Tais iniciativas individuais ou em grupo procuraram auxiliar a população em situações de necessidade.

Amalie Sieveking é um nome de grande destaque no período anterior à organização da instituição da diaconia como parte do trabalho da igreja luterana. Amalie Sieveking nasceu em uma família de comerciantes abastados de Hamburgo. A situação econômica confortável da família possibilitou-lhe o estudo privado de música e pintura, além de bordado e de economia doméstica.

A invasão de Napoleão e suas tropas na cidade de Hamburgo no ano de 1806 trouxe grandes dificuldades econômicas aos comerciantes, o que afetou diretamente a família Sieveking. Somou-se a situação já difícil, a morte de seu pai em 1809 (a mãe já havia falecido de tuberculose anos antes). Diante disso, familiares assumiram o cuidado e a orientação das crianças órfãs. Amalie foi para a casa de uma parente mais idosa que vivia da comercialização de seu artesanato. A fé e os conhecimentos bíblicos desses familiares marcaram a vida da jovem Amalie.

Ao longo de sua vida, Amalie foi uma pessoa ativa e de grande iniciativa. Fundou inicialmente uma escola para meninas pobres (1815), desenvolvendo um currículo escolar próprio. Após a morte prematura de seu irmão, fato que a abalou muito, dedicou-se à busca autônoma de conhecimentos teológicos pela leitura e junto a amigos pastores. Influenciada por teólogos místicos, procurou encontrar seu próprio caminho de fé.

Em 1832, fundou, juntamente com outras seis mulheres casadas e sete mulheres solteiras, o Weiblicher Verein für Armen- und Krankenpflege (associação feminina para o cuidado a pessoas pobres e enfermas). Através dessa cooperativa, auxiliou pessoas necessitadas por ocasião da epidemia de cólera na cidade de Hamburgo, o que significava trabalhar para combater a doença e, paralelamente, criar uma estrutura de auxílio e de esclarecimento sobre a cólera.

Apesar do muito trabalho, Amelie sempre encontrou tempo para escrever artigos teológicos, fator de crítica por parte de teólogos da época. Para ela, sempre esteve claro que suas iniciativas, tanto no campo prático, como no intelectual, ancoravam-se na fé. Suas reflexões incluíam também o debate sobre a situação da mulher. Por

\footnotetext{
12 GREINERT, Melanie. Maria Elisabeth Herzogin von Schleswig-Holstein-Gottorf, 1610-1684. Initiatorin der Schleswiger Bibel und des Husumer Hofgesangbuches. In: KLEIN; MANSKE, 2016, p. 39-43.

13 Cf. <www.rauheshaus.de>. Acesso em: 28 mar. 2017.
} 
isso foi convidada para proferir uma palestra a respeito da emancipação feminina em Berlim em 1849.

Amelie era uma pessoa ativa e uma pensadora perspicaz, que analisava criticamente o contexto ao seu redor. Através de sua fé e de seus conhecimentos bíblico-teólogicos abria caminhos na sociedade para ações práticas e para a reflexão crítica. A associação feminina para pessoas pobres e enfermas foi transformada em Fundação Amelie Sieveking, em 1978, e continua ativa até hoje. O Departamento de Mulheres da Igreja do Norte da Alemanha fez um selo em sua homenagem no ano de $1955 .{ }^{14}$

\section{Condessa Adeline von Schimmelmann (1854-1913) - Mulheres da missão}

Adeline von Schimmelmann nasceu em família nobre, tendo uma infância tranquila com aulas particulares, juntamente com suas irmãs e irmãos em Holstein. Aos 19 anos de idade, foi enviada a um internato, em Dresden, para continuar os estudos. O pai de Adeline sempre lhe foi um modelo na fé e incentivador na mesma.

O conforto da vida familiar não era foco de seu interesse, pois desejava fazer algo mais significativo em sua vida. Com a morte de seu pai, Adeline buscou consolo na fé. Como estava muito abalada, procurou um centro de descanso no litoral para recuperar-se no verão de 1886 na ilha de Rügen. Lá percebeu a difícil situação dos marinheiros, que passavam por necessidades, enfrentando fome e falta de abrigo.

Adeline decidiu fundar uma casa para ajudá-los. Comprou um terreno e construiu um lar com possibilidade para abrigar 50 moradores. E assim surgiu o primeiro lar para marinheiros no país. Adeline também morava na casa e, aos poucos, foi percebendo os problemas de seus moradores, entre eles, o do alcoolismo. Diante disso, decidiu ela mesma celebrar meditações diárias para os marinheiros, acompanhá-los espiritualmente através do aconselhamento pastoral e organizar uma biblioteca.

O trabalho frutificou e logo tornou-se conhecido também fora dos limites regionais. Representantes do governo de Berlim visitaram a ilha para conhecer melhor o trabalho da condessa. Adeline recebeu grande reconhecimento dos marinheiros sendo chamada de "Mãe". Esse destaque, adicionado à sua liderança religiosa (estudava teologia autonomamente e pregava), causou-lhe grandes dificuldades, chegando ao ponto de ser considerada mentalmente doente pela família.

A partir dessa constatação, foi internada pela família em uma clínica psiquiátrica em Copenhagen. Lá permaneceu internada por seis semanas, apesar de os médicos não terem constatado nenhuma doença psiquiátrica. Os amigos solidarizaram-se com Adeline e divulgaram o ocorrido. Como ela era internacionalmente conhecida, notícias e comentários foram publicados em jornais.

Adeline utilizou seus contatos para mobilizar doações a fim de abrir mais lares para marinheiros no litoral do mar Báltico. Também passou a trabalhar na publicação

\footnotetext{
${ }^{14}$ SUHR, Ulrike. Frauen in der Diakonie der Neuzeit. In: KLEIN; MANSKE, 2016, p. 60-63; GESTNER, Uta. Amalie Sieveking, 1794-1859. „Mein Geschlecht zu einer höheren Wirksamkeit erheben...“. In: KLEIN; MANSKE, 2016, p. 69-73.
} 
de material evangelístico e na pregação. Por ter estudado teologia autonomamente, não é possível incluir seus escritos em uma linha única de pensamento dentro das tradições cristãs, pois revelam influências diversas da fé cristã.

Apesar do seu grande engajamento social e de suas inúmeras iniciativas, Adeline morreu só e pobre em Hamburgo. Alguns autores atribuem a ela o início da promoção do trabalho denominado hoje de Missão aos Marinheiros. ${ }^{15}$

\section{Elisabeth Haseloff (1914-1974) - a primeira pastora}

Elisabeth Haseloff foi a primeira pastora da Alemanha. Para assumir esse cargo foi necessário um longo trajeto. O pai de Elisabeth era professor universitário de história da arte e, em sua casa, era comum o encontro com especialistas nas áreas das ciências e das artes. A morte prematura de seu irmão abalou-a e foi no ensino confirmatório que Elisabeth encontrou consolo através da palavra de Deus. Logo após a confirmação, Elisabeth declarou que queria estudar teologia.

Em Marburgo, no ano de 1925, fundou a Associação Evangélica de Teólogas da Alemanha com o objetivo de rever os regulamentos dos exames e de ampliar as possibilidades de trabalho para teólogas. A partir de 1935, realizou seus estudos de teologia em Tübingen, Erlangen e Kiel. Durante o período de estudos, juntou-se ao grupo de teólogos e teólogas que faziam oposição ao Regime Nazista, denominado de Bekennende Kirche (Igreja Confessante). Em 1939, realizou seus exames de final de curso.

Logo após, iniciou seu vicariato (residência pastoral) em Neumünster, pois, devido ao início da Segunda Guerra Mundial, Elisabeth não pode seguir os planos de ir aos Estados Unidos para um intercâmbio. No vicariato, dedicou-se principalmente ao aconselhamento pastoral no hospital. Devido ao volume de trabalho, seu mentor, pastor Treplin, permitiu que ela o substituísse no trabalho pastoral da comunidade, apesar de isso não ter sido previsto pela Igreja Territorial. Dessa forma, Elisabeth pode pregar, fazer estudos bíblicos e realizar todas as demais atividades pertencentes a esse cargo.

Depois de prestar o segundo exame teológico em 1941, não foi ordenada como seus outros três colegas. Então, o que fazer? Antes de mais nada, terminou seu doutorado, depois decidiu fazer um vicariato em Rendburg. Na época, o vicariato era a única possibilidade de trabalho para mulheres que haviam se formado em Teologia. Ainda em Rendburg, Elisabeth Haseloff foi convidada a assumir uma paróquia vaga, pois muitos pastores haviam sido enviados para a guerra. Para assumir o cargo, era necessária a ordenação. O pastor Treplin realizou a ordenação de Elisabeth Haseloff, apesar dela não ter sido regulamentada pela direção da Igreja Territorial.

Ao final da guerra, os pastores retornaram aos seus antigos campos de trabalho, obrigando a quem os havia substituído a retirar-se. A partir desse momento, iniciou um período de debate sobre o pastorado de mulheres entre a direção da Igreja Territorial, as comunidades e Elisabeth. Elisabeth defendeu a ideia de que a comunidade

\footnotetext{
15 MANSKE, Maike. Adeline Gräfin von Schimmelmann (1854-1913). „... Sehnsucht nach etwas Höheren“.
} In: KLEIN; MANSKE, 2016, p. 103-107. 
deve também decidir sobre as tarefas das vicárias (não havia ainda a denominação "pastora"). Ou seja, ela defendeu o diálogo e não a imposição de uma decisão hierárquica sobre a questão.

Em 1945, a comunidade de Büdelsdorf decidiu a favor da permanência da "Senhora Vicária" (Frau Vikarin) na comunidade. Na casa pastoral, as vicárias passaram a se reunir para tratar de questões relacionadas aos estudos e ao trabalho. O tema central era a definição das atividades para as vicárias. $\mathrm{O}$ desejo era o de não restringi-las unicamente ao trabalho de acompanhamento para mulheres.

Em 1959, o distrito de Lübeck decidiu oferecer um trabalho pastoral voltado para mulheres, a ser ocupado por Elisabeth. O diferencial aqui é que essa era uma vaga pastoral e não de vicariato. Isso foi possível depois de uma modificação na lei do país sobre a igualdade para homens e mulheres, seguida pela modificação nas leis da igreja no ano anterior. Assim, Elisabeth assumiu o trabalho pastoral na comunidade de São Mateus com a tarefa extra de coordenar o trabalho com mulheres no âmbito regional.

Esse trabalho atingiu uma dimensão tal que Elisabeth pediu afastamento da comunidade (1966), a fim de dedicar-se somente às atividades com as mulheres. O distrito de Lübeck concordou e fundou uma casa para esse fim com o nome de Elisabeth-von-Thadden-Haus. A pastora Dra. Elisabeth Haseloff faleceu em um acidente de carro em 1974 em Hamburgo.

\section{Gênero e Reforma - análise de gênero}

A exposição itinerante do Departamento de Mulheres da Igreja do Norte da Alemanha busca resgatar histórias de mulheres que, desde o movimento da Reforma no século XVI até hoje, testemunham sua fé na igreja e na sociedade. O encontro com tais biografias leva ao diálogo sobre questões relacionadas à vida das mulheres e dirige o olhar para a análise de gênero.

Os confrontos e conquistas encontrados nas biografias aqui resumidas são fruto do questionamento da ordem social estabelecida conforme a divisão de tarefas por gênero. O questionamento surge na ocupação de cargos de liderança ou no desejo de ocupá-los, na participação no debate teológico, na pregação e na iniciativa de novos projetos.

Gênero é uma categoria de análise histórica que surgiu dentro dos estudos feministas dos anos 80 do século passado. Seu enfoque recai sobre a definição de normas e papéis na sociedade a partir do masculino e do feminino. Joan Scott, historiadora norte-americana, é uma das pioneiras na formulação desse conceito. Ao pesquisar o tema da sustentabilidade a partir de um modelo de liderança de mulheres, Adriana Gastellú Camp apresenta um estudo sobre gênero como categoria de análise histórica. ${ }^{16}$

${ }^{16}$ CAMP, Adriana Gastellú. Como espiral de vida, aportes de la Teología Feminista de Liberación para otros modelos de liderazgo en las Iglesias de América Latina y el Caribe. São Leopoldo: Faculdades EST; Instituto Sustentabilidade América Latina e Caribe, 2015. p. 74-81. 
A leitura das biografias aqui resumidas permite, em uma análise de gênero, o diálogo com a proposta dos papéis masculinos e femininos a partir do movimento da Reforma. Nessa perspectiva, os temas mais presentes são: a educação para meninas e meninos, o casamento (celibato e sexualidade), a igualdade de direitos pastorais para mulheres e homens, ética e religião (proposta de igualdade a partir do sacerdócio universal de todos os crentes), novas iniciativas. Uma pergunta quer impulsionar a reflexão: por que houve uma participação tão grande por parte das mulheres no movimento da Reforma?

A fim de responder a essa pergunta, algumas constatações são importantes. Primeiramente, o pensamento teológico de Lutero sobre o sacerdócio universal de todos os crentes gerou e gera participação. Muitas mulheres se sentiram chamadas, incluídas nesse movimento religioso. Por isso escreveram seus pensamentos teológicos, divulgaram em seu meio as novas ideias de fé e, corajosamente, iniciaram trabalhos sociais junto a pessoas necessitadas.

Segundo, a ideia de igualdade veio ao encontro daquelas pessoas que buscavam por algo novo na sociedade e na vivência religiosa no século XVI. A proposta de igualdade gerava a possibilidade de ocupar outros espaços na sociedade, na igreja e nas relações sociais. Ao sentirem-se incluídas, as mulheres participam ativamente. Por isso passam a envolver-se com questões sociais, intelectuais e de direitos.

Igualdade entre os gêneros e participação social a partir da fé oportunizava um novo Dasein, uma nova forma de se colocar no mundo, bem como uma nova forma de compreender o mundo e suas relações. Pela primeira vez, muitas mulheres puderam participar ativamente de um movimento religioso com a perspectiva de não serem discriminadas e, paralelamente, construírem em conjunto uma nova definição do papel da mulher na sociedade e na igreja.

Destaca-se aqui a compreensão de que as mulheres da Reforma, no século XVI, colaboram ativamente na elaboração das novas ideias. Há teólogas hoje que chamam a atenção para uma análise de documentos sob esse enfoque. Para elas, as mulheres não apenas colaboram na divulgação da nova fé, mas são parte integrande / formadora de seus conteúdos. E, nesse aspecto, há um grande avanço. A tradição costuma destacar os grandes teólogos da época como Martim Lutero e Ulrich Zwínglio, por exemplo, sem enfatizar a contribuição de mulheres para o pensamento teológico da época.

Uma mudança de olhar permite outra percepção das mulheres na Reforma. Segundo essa análise, a formulação do sacerdócio universal de todos os crentes, bem como as propostas de educação, do casamento e da valorização da mulher na nova fé já estão imbuídos do diálogo com mulheres e de sua reflexão crítica. ${ }^{17}$ É a formulação conjunta de um novo Dasein.

${ }^{17}$ KÄSSMANN, Margot. Endgültig beantwortet, die Beteiligung der Frauen an der Reformation war exemplarisch für deren Inhalte. Cf. <www.zeitzeichen.net/religion-kirche/frauen-der-reformation>. Acesso em: 21 mar. 2017. 
O modelo de educação da Reforma busca uma formação básica para meninos e meninas. Esse é um grande avanço, pois oferece a mesma oportunidade para ambos os sexos. Apesar de a proposta ter por objetivo o preparo da mulher para o casamento e para a vida familiar, ela é muito positiva, pois oportuniza uma formação básica (matemática, contabilidade, escrita e leitura) para as meninas. Através da educação, a mulher define um lugar de respeito na família e sociedade, pois passa a dominar saberes e assumir a função de educadora dos filhos e das filhas, além da responsabilidade da economia doméstica.

Apesar dos avanços, o novo modelo de educação não deixa de apresentar falhas, recebendo, por isso, algumas críticas. A maior crítica é que o modelo não prevê uma educação em níveis mais avançados para as meninas, como acontecia anteriormente nos conventos. $\mathrm{O}$ debate sobre a continuação dos estudos para as meninas veio à tona somente com o Iluminismo. ${ }^{18}$ Até então, compreendia-se que o estudo até a confirmação bastava para se cumprir o papel que era definido à mulher.

O casamento também passou a ser um tema no movimento da Reforma, sendo abordado em prédicas e textos. Lutero escreve: "O homem deve sustentar a família através de seu trabalho e deve tratar sua esposa de forma tolerante e amigável. A esposa lhe deve obediência, ter crianças e educá-las na fé evangélica"19. Além disso, o casal deve ser fiel. A sexualidade passa a ser vista de forma positiva, pertencente à natureza humana e ambos no casamento são responsáveis pela sua vivência.

A visão positiva e natural da sexualidade também é uma novidade, que vem com a clara recomendação de ser desfrutada em uma relação de fidelidade. Assim, os papéis e as tarefas vão aos poucos se sedimentando para as pessoas que participam do movimento da Reforma. Era importante que o modelo de casamento atingisse sucesso entre as famílias de teólogos e futuros pastores, pois esses deveriam ser exemplo para o restante da sociedade.

Fato é que as mulheres foram sobrecarregadas em termos de tarefas nesse modelo conjugal ideal. Com o cuidado da casa, da família e da prole, pouco tempo restava para se dedicar à leitura e ao aprofundamento teológico. Além disso, a vida conjugal representava um desafio para os ex-monges e para as ex-freiras, que estavam acostumados à vida no convento.

Nem todas as ex-freiras optaram pela vida conjugal. Essa escolha tornou-se uma questão problemática por dois motivos: primeiramente, como iriam sustentar-se as mulheres solteiras? Segundo, um outro modelo de vida não poderia colocar em cheque a proposta luterana de família ${ }^{20}$ Que identidade teriam essas mulheres? Dessa forma, o casamento era colocado como modelo ideal de vida, recebendo constantes impulsos para ser desejado pelas mulheres.

${ }^{18}$ CONRAD, Anne. Vom Evangelium zur Ehe. Frauen in der Zeit der Reformation. In: SCHATTKOWSKY, Martina. Frauen und Reformation, Handlungsfelder-Rollenmuster-Engagement. Leipzig: Leipziger Universität, 2016. p. 40-52.

19 CONRAD, 2016, p. 46.

${ }^{20}$ CONRAD, 2016, p. 47. 
Outro problema era a situação das viúvas e seus filhos e filhas. Sem uma profissão definida, tornava-se muito difícil sustentar a família em sua nova constituição. $\mathrm{O}$ que fazer nessa situação? De onde tirar o sustento sem uma profissão definida? Quem deveria assumir a responsabilidade nesses casos? Muitas viúvas pediram ajuda para suas comunidades para poder enfrentar a situação. Assim, o questionamento sobre os papéis agora definidos para homens e mulheres retornava. Seria melhor permanecer no convento ou casar e enfrentar a incerteza do futuro ${ }^{21}$

Se, apesar dessas dificuldades, havia uma proposta clara de igualdade através do sacerdócio universal de todos os crentes, por que aos poucos as mulheres se afastam da liderança de comunidades e da igreja, restringindo-se à esfera doméstica? Segundo Anne Conrad, algumas dessas mulheres provavelmente deixaram de publicar seus pensamentos teológicos à medida que as comunidades luteranas foram se consolidando e sendo lideradas por pregadores e teólogos, os quais possuíam formação teológica. ${ }^{22}$ Como o seu papel estava definido a partir do casamento e da maternidade, esse passou a ser o seu espaço de movimentação.

O exemplo das mulheres no trabalho de missão, aqui abordado através da biografia de Adeline von Schimmelmann, abre um novo capítulo para a igreja em Reforma a partir do final dos anos de 1880. As iniciativas das mulheres na missão vêm ao encontro da necessidade de um determinado contexto. No entanto, parece que nem a sociedade nem a igreja sabiam ao certo como lidar com essas mulheres, e a primeira reação foi a da repreensão.

Reprimir a iniciativa parecia ser a única solução para o conflito, pois tais mulheres não cabiam no modelo social a elas previsto. Pregar, aconselhar e liderar eram ações consideradas masculinas. Ao assumir tais lugares, as mulheres causavam deslocamento e desconforto, desafiando à reflexão tanto em relação à situação de necessidade, quanto a novas possibilidades de liderança, o que certamente também gerava disputa de poder.

Há casos em que a igreja manteve uma observação à distância dessas mulheres quando elas retornaram do trabalho no exterior. Somente depois, ao constatar as dificuldades pelas quais as missionárias não casadas passaram em idade avançada (doença e isolamento), é que foram propostas formas de auxílio financeiro e de cuidado para aquelas que se dedicaram à educação e à saúde na missão. ${ }^{23}$

A partir do período entre guerras, surge outra situação que aponta para o conceito de igreja sempre em Reforma. O tema agora é a ordenação de mulheres e o pastorado para mulheres. Elisabeth Haseloff conduziu o debate sobre a ordenação e o pastorado para mulheres juntamente com colegas vicárias e outras pessoas abertas ao debate da questão. $\mathrm{O}$ sucesso desse processo beneficia toda a igreja, pois vem ao encontro da busca por igualdade, promovida pelo sacerdócio universal de todos os crentes.

${ }^{21}$ ZINSMEYER, Sabine. Fliehen oder bleiben? Nonnen in der Reformationszeit. In: CONRAD, 2016, p. 287-302.

${ }^{22}$ CONRAD, 2016, p. 41.

23 JORDAN, Britta; PAULSEN, Ulrike. Ann Asmussen, 1871-1958, von der Senana-Dame zur Missionarin - Schritte zum eingeständigen Frauenberuf. In: KLEIN; MANSKE, 2016, p. 113. 
A história de persistência na busca pelo estudo de teologia, seguido pelo pastorado para mulheres não ocorreu somente na Alemanha. Gastellú Camp cita, em sua pesquisa de mestrado, a história da conquista do pastorado de mulheres e demais direitos na IECLB (Igreja Evangélica de Confissão Luterana no Brasil). ${ }^{24}$ Percebe-se, assim, que o questionamento de papéis e normas previamente definidos para homens e mulheres, na igreja, não ocorreu em um único lugar. Certamente, a conquista de novos espaços para mulheres na liderança, em um determinado espaço, auxilia essa mesma conquista em outros contextos.

Novamente aqui há uma situação de confronto e disputa de poder, pois os papéis sociais referentes ao masculino e ao feminino são questionados. $\mathrm{O}$ que significa a possibilidade de uma mulher pregar e liderar uma comunidade? Que deslocamentos são neles propostos? Quem os teme? Pregar e liderar significar falar de ideias, de fé e impulsionar outras formas de organização. Quando mulheres assumem essa tarefa, novas possibilidades se abrem e uma reestruturação toma lugar.

A exposição itinerante traz ao público ainda outras histórias que possibilitam a continuação dessa análise. Tal tarefa é desafio para um futuro trabalho. Outro tema para um futuro trabalho relacionado ao tema proposto neste artigo refere-se à teologia desenvolvida por teólogas. Quais são as ênfases e os temas abordados?

A teóloga mais conhecida da Igreja do Norte da Alemanha é Dorothee Sölle. Sölle aprofundou o tema da mística e da resistência em suas últimas pesquisas. Para Sölle, a busca por justiça é justificada pela relação com Deus, uma relação mística. ${ }^{25}$ Essa proposta retoma o tema da mística abordado por algumas mulheres da Reforma e também enfatiza a participação das mulheres no pensamento teológico de mulheres desde o movimento da Reforma até hoje.

\section{Considerações finais}

A história das mulheres no movimento da Reforma é composta por momentos de avanço e de retrocesso. Inicialmente, as mulheres sentiram-se livres e impulsionadas para participar da oferta de um novo Dasein, inspiradas pelo pensamento de Lutero sobre o "sacerdócio universal de todos os crentes". Pensamento esse que continuou e continua a inspirar inúmeras mulheres a dar seu testemunho de fé e de buscar igualdade e participação, tanto na igreja como na sociedade.

Infelizmente, a história nos mostra que a institucionalização da igreja, em alguns momentos, pendeu para uma nova organização hierárquica atingindo diretamente a participação de mulheres na liderança. Como somente os homens, por um longo período de tempo, tiveram a permissão de estudar teologia, as mulheres foram paulatinamente afastadas da liderança das comunidades e da igreja, bem como do pensamento teológico.

${ }^{24}$ CAMP, 2015.

${ }^{25}$ SÖLLE, Dorothee. Mystik und Widerstand. „Du stilles Geschrei“. Freiburg im Breisgau: Kreuz, 2014. 
Com muita persistência, mulheres voltaram a ocupar lugares de liderança nas comunidades, no âmbito teológico e na igreja. Percebe-se, dessa forma, que a ideia de igualdade e de participação promovida por Lutero continua sendo extremamente desafiadora e atual. Infelizmente, ainda há desequilíbrio em representações e ocupação de cargos entre homens e mulheres. Uma política de gênero voltada para cotas procura superar essa desigualdade em muitas igrejas luteranas.

A exposição itinerante do Departamento de Mulheres da Igreja do Norte da Alemanha demonstra a importância do resgate de histórias de mulheres. Paralelamente, lança o desafio a seus visitantes de buscarem descobrir histórias em suas comunidades relacionadas ao tema e, quem sabe, o encontro de um número ainda maior de histórias de mulheres envolvidas ativamente na vida de uma igreja sempre em Reforma.

O encontro com essas biografias é marcante. Seu testemunho de fé, a convicção de igualdade e o desejo de participação levaram muitas mulheres a iniciativas corajosas. Suas conquistas trazem hoje benefícios não só para mulheres, mas também para toda a sociedade. Repensar as normas sociais para mulheres e homens, bem como modelos de liderança é uma exigência constante na busca pela igualdade.

\section{Referências}

CAMP, Adriana Gastellú. Como espiral de vida, aportes de la Teología Feminista de Liberación para otros modelos de liderazgo en las Iglesias de América Latina y el Caribe. São Leopoldo: Faculdades EST; Instituto Sustentabilidade América Latina e Caribe, 2015.

CONRAD, Anne. Vom Evangelium zur Ehe, Frauen in der Zeit der Reformation. In: SCHATTKOWSKY, Martina. Frauen und Reformation, Handlungsfelder-Rollenmuster-Engagement. Leipzig: Leipziger Universität, 2016.

DORMRÖSE, Sonja. Frauen der Reformationszeit, gelehrt, mutig und glaubenfest. Göttingen: Vandenhoeck \& Ruprecht, 2014.

JORDAN, Britta; PAULSEN, Ulrike. Ann Asmussen, 1871-1958, von der Senana-Dame zur Missionarin - Schritte zum eingeständigen Frauenberuf. In: KLEIN, Kerstin; MANSKE, Maike. „,...von gar nicht abschätzbarer Bedeutung “. Frauen schreiben Reformationsgeschichte. Kiel: Lutherische Verlagsgesellschaft, 2016.

KLEIN, Kerstin. „...von gar nicht abschätzbarer Bedeutung“. Frauen schreiben Reformationsgeschichte, ein partizipatives Ausstellungsprojekt. In: KLEIN, Kerstin; MANSKE, Maike. „,...von gar nicht abschätzbarer Bedeutung “. Frauen schreiben Reformationsgeschichte. Kiel: Lutherische Verlagsgesellschaft, 2016.

KOERTGE, Ulrike. 500 Jahre Reformation - und Frauen sind machtvoll dabei! Vorwort. In: KLEIN, Kerstin; MANSKE, Maike. ,, ...von gar nicht abschätzbarer Bedeutung “. Frauen schreiben Reformationsgeschichte. Kiel: Lutherische Verlagsgesellschaft, 2016.

MURY, Nanna; MANSKE, Maike. Wibe Jung, ca. 1485 - unbekannt, „Da trat hinzu eine fromme christliche Frau, wohnhaft zu Meldorf“. In: KLEIN, Kerstin; MANSKE, Maike. „...von gar nicht abschätzbarer Bedeutung “. Frauen schreiben Reformationsgeschichte. Kiel: Lutherische Verlagsgesellschaft, 2016.

SÖLLE, Dorothee. Mystik und Widerstand. „Du stilles Geschrei“. Freiburg im Breisgau: Kreuz, 2014. 
ZINSMEYER, Sabine. Fliehen oder bleiben? Nonnen in der Reformationszeit. In: SCHATTKOWSKY, Martina. Frauen und Reformation. Handlungsfelder-Rollenmuster-Engagement. Leipzig: Leipziger Universität, 2016.

\section{Sites consultados}

<www.nordkirche.de>. Acesso em: 21 mar. 2017.

$<$ www.zeitzeichen.net/religion-kirche/frauen-der-reformation>. Acesso em: 21 mar. 2017.

$<$ www.nordkirche.de/de.wikipedia.org/wiki/Maria_Jensen>. Acesso em: 27 mar. 2017.

$<$ www.rauhenhaus.de>. Acesso em: 28 mar. 2017. 